\title{
One Drive Master
}

\author{
Khaleel Alkandari ${ }^{1}$, Meshal Aldhamen ${ }^{2}$ \\ Public Authority for Applied Education and Training, Dept of Computer, \\ The Higher Institute of Telecommunication \& Navigation, Kuwait City, Kuwait ${ }^{1,2}$
}

\begin{abstract}
Microsoft developed the one drive master, which allows people to store pictures, images, documents, files and music on the cloud. The drive is an important invention in the $21^{\text {st }}$ century, and it is a reflection of the progress in technology. The only thing an individual needs to access the drive is an account with Microsoft. With the account, saving takes place by default. Besides, the process of saving documents, files, music and pictures on the cloud is easy. Apart from saving, it is possible to share the saved items with other people. Although some people perceive the one drive master as irrelevant, such a perception is misguided. There are many benefits of having the one drive master. In particular, the one drive master serves as a backup system, meaning that one does not need a machine to access files. One only requires an internet connection, and regardless of the location, files are accessible.
\end{abstract}

Keywords: One Drive, Drive Master, Sharing, Cloud, Sync.

\section{INTRODUCTION}

The one drive master is the most recent advancement in technology. The drive stores things on the cloud, and with an internet connection, one can access files from anywhere. The drive has many benefits. Therefore, there is a need to explore how it works, in terms of saving and sharing images, pictures, files and documents with people.

\section{CLOUD STORAGE}

The one drive master is space provided by Microsoft. Furthermore, it offers free storage of documents, pictures, music and other things on the cloud. Anyone can access the one drive, with the only condition being that, one must have a Microsoft account (Microsoft, 2015). Formerly, Microsoft's cloud storage was the Sky Drive. Currently, cloud storage platform is available for desktops, laptops and mobile phones. When one saves documents using one drive master, the cloud serves as the backup.

Therefore, even with the backup system in the system, the cloud storage is more effective. Accessing the cloud storage requires one to have a Microsoft account, which facilitates storage on the cloud by default. However, one must select the "Save documents to one drive by default," option. The option is accessible from the settings by selecting Change PC settings, One Drive and File storage. There is a need for checking the setting regularly to ensure proper storage (Nield, 2015). In other words, the one drive master is an additional drive, which is accessible through a laptop, desktop or mobile phone.

\section{ONE DRIVE MANAGEMENT}

Managing the one driver master requires a suite. The suite will help in identifying the available content, level of user activity; thus, facilitates appropriate actions. The management suite has all tools to ensure the drive's performance is optimal (Branscombe, 2014). Furthermore, management suite plays other important roles, which are,

- The suite makes information on user activity, growth of data and the trends of usage easily available.
- The suite makes it easy to migrate and separate content. For example, the suite separates personal and public content.

- The suite serves as a backup for critical content (Microsoft, 2015).

\section{PREVENTING DATA LOSS}

Cloud storage is an important discovery. Cloud storage allows people to access data from any location using any device. However, such indiscriminate entry or access to data is somehow dangerous. In fact, there are sensitive data; thus, it is not advisable to access such through any device. Therefore, one of the methods of protecting data is through accessing cloud data from a single device. Furthermore, there is another change, which Microsoft implemented, with an aim of preventing data loss. The one drive master has a unified sync client, and there is a version for enterprises and personal use. Besides, Microsoft has added a Data Loss Prevention tool. Such a tool allows the administrators to set up policies that will help in preventing the loss of data. In addition, there is a need of using cloud storage appropriately, especially when accessing it through public computers. Therefore, people should ensure they log out from public computers to avoid potential intrusion to the cloud storage (Kaelin, 2015).

\section{SHARING WITH SHAREPOINT ONLINE}

Initially, SharePoint aimed at offering basic storage for company documents. Through evolution, SharePoint encompassed My Site, which allowed people to sort personal files, photos, or folders. Notable, SharePoint was accessible through the network; thus, Microsoft developed the one drive, which allowed for cloud storage. Nonetheless, SharePoint and one drive have redefined cloud storage, and accessibility of files, pictures and others, remotely (Wlodarz, 2014). SharePoint aims at sharing, and some of the sharable things include the intranet, business documents and allows for integration of 
services and applications. On the other hand, one drive aimed at providing an approach to store personal items such as documents, files, pictures and folders. Therefore, the SharePoint serves as a central location where staffs can collaborate. However, one drive has a limitation to the individual level; thus, it does not foster collaboration between the staffs. The two, SharePoint and one drive facilitate document editing. The procedure for sharing the documents is similar in both SharePoint and one drive. In particular, one needs to identify the relevant document, right click on the document and share, accordingly. Then again, SharePoint and one drive facilitate document searching, and document sharing (Carter, 2015).

\section{SHARING DOCUMENT}

The one-drive master makes it easy to share documents with people regardless of their locations. The functionality allows access to documents; thus, people can edit documents. It is important to note that, the procedure of sharing a document is more or less similar to the process of sharing a file. However, sharing a document encompasses some security, for example, the ability to edit or view the document. The process of sharing a document is easy and involves the following steps.

- Place the mouse over the relevant document.

- Tap or click the box that emerges.

- Identify the sharing group, and then, tap share.

- In the pop-up window, enter relevant email address, and click share.

- Besides, one can edit the permissions for the other party to either view or edit the document.

- When sharing a folder, one will have to confirm their choice, by tapping the share this folder option. However, the option is not available for files.

- An easier way of sharing a document involves clicking the file or folder to select, and then, clicking the share button that appears at the top of the page (Blaga, 2014).

\section{SHRINKING FILES}

One of the ways of creating space on the one drive master is enabling the compress option, which will help in shrinking files. Like sharing documents, the process is quite easy, and it involves the steps below.

- Locate the one drive icon and right click for more options.

- Choose the properties option and click the general tab.

- Then, click on the advanced option.

- On the advanced pop-up, see the last part identified as compress or encrypt attributes.

- Check the box labelled compress contents to save disc space.

- On that part, click the OK and APPLY buttons (Valdosta, 2014).

\section{SHARING PICTURE}

The one drive master serves as a backup for pictures, files, videos or music to storage on the cloud. Furthermore, another important feature of the drive is making it easy to share the files, pictures or music from any location (Microsoft Corporation, 2014). Like previously mentioned procedures, sharing pictures from the drive is easy.

- Access the Microsoft account.

- Identify the picture for sharing.

- Right click the picture, and select the share option.

- A pop-up will emerge, which requires one to invite people.

- Provide the email addresses.

- Select whether the recipients can either view or edit the pictures.

- Select other options, whether recipients must have a Microsoft account or do not need the account to access the pictures.

- Click on the share option (Fingas, 2015).

\section{CACHE FILES FOR OFFLINE ACCESS WINDOWS}

Although the one drive master stores files online by default, the files are downloadable. It is important to note that, in an event of internet breakdown, problems may arise. Nonetheless, the one drive master allows for offline access to the files. Although storing files locally will take up much space on the hard drive, it is worth because of the unpredictable nature of the internet. The process of making the files accessible offline is an easy one. Just right click on the relevant file or the folder stored in the one-drive master, and selects the make available offline option. In addition, one can cache everything by right clicking on the one drive entry through the navigation plane (Nield, 2015).

\section{SAVE ATTACHMENT FOR OUTLOOK AND OTHER MAIL}

The drive has provided a simpler way for saving and managing email attachments. The feature is available for outlook and other emails. All the attachments received by email are added to the drive's folder known as Email Attachments, which allows for ease of finding and subsequent sharing. One can choose what to save by clicking on the relevant attachment, and subsequently clicking the save to one drive option. Furthermore, it is possible to save the attachments to the local drive by first downloading them either individually or all together (Shiled, 2015). On the other hand, for people using emails from other providers other than Outlook, can save the attachments, but they have to download them first. Consequently, they can select the downloaded attachments and save them on the cloud. However, the process is easy for outlook emails because it eliminates the task of saving attachments to the local drive, and then, uploading to the drive. Apparently, when the attachments are in the onedrive master, they will appear on all the user's devices (Nield, 2015).

\section{SEARCH INSIDE FILES AND PHOTOS}

The drive allows for searching files, photos and other saved items. Therefore, running a search in the drive will 
International Journal of Advanced Research in Computer and Communication Engineering

Vol. 4, Issue 12, December 2015

help in retrieving the relevant items. Apparently, the drive uses the optical character recognition technology, which helps in finding the relevant texts. Apparently, the search functionality is similar to the one in laptops, or desktops. One only needs to text the name of the file, or photo and click on the search button (Perez, 2014). The only condition for search to work is that, one must remember the names given to folders, files or photos. Besides, the photos, files or folders must be named for ease of searching.

\section{PIN FOLDER TO ANDROID HOME SCREEN}

Another important feature of the one drive is the capability of creating widgets on the home screen. Pinning folders on the home screen is an easy task, which involves tapping and holding on blank sections of the home screen. Then, one should select the one drive, which further allows for choosing relevant folders to pin on the home screen. The feature is important because it gives people a chance to access quickly important folders (Nield, 2015).

\section{EMBED PRESENTATIONS ANYWHERE}

A one-drive master makes it easy to embed presentations. While cloud storage services allow people to embed presentations, the one drive master makes the task simple. The embedded presentation is downloadable, or embeddable when made available (Nield, 2015). For one to embed presentations they should follow the steps below,

- Visit the Microsoft's one-drive website, and open the PowerPoint presentation that they want to embed.

- The file menu has several options. Click on the share, then, embed.

- A blue "Generate" button will come up. Click it to produce the HTML code.

- There is an outcome code, which one should copy.

- Paste the generated code into a text editor.

- When one updates the post or page, the code will change to a short code.

- After publishing the page or post, the embedded presentation will convey the required image or message (Microsoft, n.d).

\section{USE SELECTIVE SYNC ON WINDOWS}

The one drive master can synchronize files, selectively on Windows System. Selective sync means that, one can choose files to synchronize from the drive to the computer. The feature is important as it allows people to either upload or download without having to move all files to another computer (Nield, 2015). The steps below present how to use the one drive master to synchronize files.

- Check the one drive icon on the taskbar, right click on it, and click settings.

- Click on the choose folders.

- Two options will emerge, and one is to choose the files, or folders they want to sync.

- The selected files or folders will synchronize on the computer (Windows Ten Forums, 2014).

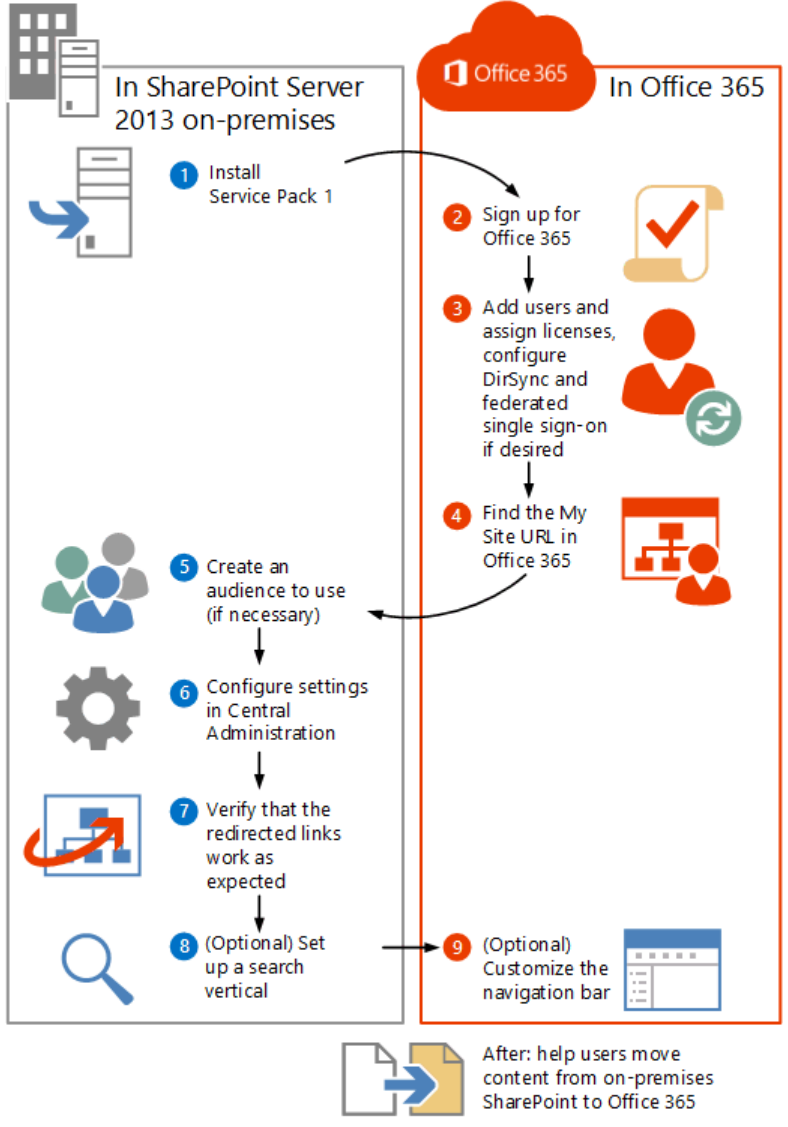

FIGURE1 THE FOLLOWING FIGURE DEMONSTRATE THE FLOW IN SHARE POINT SERVER.

In this paper, the one drive master has been explored, comprehensively. Clearly, the drive is beneficial and people should consider applying for an account with Microsoft. In light of the rapid technological advancement, and the uncertainty of storing things in removable media, the cloud offers a permanent solution.

\section{REFERENCES}

[1] Blaga, M. (2014). How to share files and folders using the one drive website. Retrieved from http://www.7tutorials.com/how-share-filesand-folders-using-onedrive-website.

[2] Branscombe, M. (2014). How to set up and managing one drive for business. Retrieved from http://blog.pluralsight.com/microsoftonedrive-for-business.

[3] Carter, N. (2015). Mind your business with one drive and SharePoint. Retrieved from https://redmondmag.com/articles/2015/08/01/onedrive-andsharepoint.aspx.

[4] Fingas, J. (2015). Microsoft's One Drive gets better at showing and sharing your photos Retrieved from http://www.engadget.com/2015/01/29/onedrive-photo-revamp/

[5] Kaelin, M. (2015). Better data loss prevention tolls for one drive for business. $\quad$ Retrieved from http://www.techrepublic.com/article/better-data-loss-preventiontools-for-onedrive-for-business/

[6] Microsoft Corporation. (2014). One drive how to. Retrieved from https://onedrive.live.com/about/en-us/support/

[7] Microsoft. (2015). Using one drive on surface. Retrieved from http://www.microsoft.com/surface/en-us/support/storage-files-andfolders/onedrive-on-surface?os=windows-10

[8] Microsoft. (2015). MetaVis one drive management suite. Retrieved from https://pinpoint.microsoft.com/enbi/Applications/12884982995 
[9] Microsoft. (n.d.). Microsoft One Drive PowerPoint Web App. Retrieved from https://en.support.wordpress.com/powerpoint-webapp/

[10] Nield, D. (2015). 10 tricks to make yourself a One Drive master. Retrieved from http://fieldguide.gizmodo.com/10-tricks-to-makeyourself-a-onedrive-master-1683618001

[11] Perez, C. J. (2014). Microsoft's one drive for business now an option with office online. Retrieved from http://www.computerworld.com/article/2488192/socialbusiness/microsoft-s-onedrive-for-business-now-an-option-withoffice-online.html

[12] Shield, J. (2015). Save your outlook.com email attachments to one drive in one click. Retrieved from https://blogs.office.com/2015/01/14/save-outlook-com-emailattachments-onedrive-one-click/

[13] Valdosta. (2014). Office 365: Share documents or folders in one drive for business. Retrieved from http://www.valdosta.edu/administration/it/helpdesk/documents/one drive-share.pdf

[14] Windows Ten Forums. (2014). OneDrive selective sync: Choose folders in Windows $10 . \quad$ Retrieved from http://www.tenforums.com/tutorials/2905-onedrive-selective-syncchoose-folders-windows-10-a.html

[15] Wlodarz, D. (2014). Dump the file server: Why we moved to the SharePoint online cloud. Retrieved from http://betanews.com/2014/03/24/dump-the-file-server-why-wemoved-to-the-sharepoint-online-cloud-review/

\section{BIOGRAPHY}

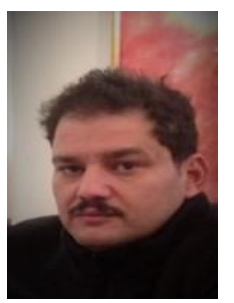

Professor Meshal Aldhamen Work for The Higher Institute of Telecommunication \& Navigation. Department Of Computer Technology, Kuwait.Citrix Certified Administrator (CCA), Citrix Certified Instructor (CCI), A+ Certification, Empire WHO's WHO Award. 